\title{
Representações sociais construídas sobre os índios em Sergipe: ausência e invisibilização ${ }^{1}$
}

\author{
Marcus Eugênio Oliveira Lima ${ }^{2}$ \\ Alan Magno Matos de Almeida \\ Universidade Federal de Sergipe, São Cristovão-SE, Brasil
}

\begin{abstract}
Resumo: O objetivo do estudo foi analisar as representações sociais construídas pelos sergipanos sobre os índios. Foram entrevistados 378 moradores de seis cidades (cinco em Sergipe e uma em Alagoas). Os resultados obtidos indicam o predomínio de uma representação social cujo núcleo central é formado por elementos que referem um tempo passado e remoto, ou que denotam a distância física e cultural (como "matas", "florestas", "nudez", "pintura"). Igualmente, quando perguntados sobre o que lembram dos índios na história do Brasil, os entrevistados raramente referem acontecimentos recentes e têm mesmo dificuldade para produzir qualquer enunciação. $\mathrm{O}$ fato de morar longe ou perto de uma tribo indígena teve menos impacto nas representações sociais do que esperávamos. As conclusões indicam que, para muitos dos pesquisados, os índios existem apenas como uma ausência ou ainda de um modo naturalizado, como reminiscências fenotípicas e culturais de uma história de 500 anos de violência e extermínio.
\end{abstract}

Palavras-chave: índios, representação social, estereótipos.

\section{Social representation about Indians in Sergipe: absence and invisibility}

\begin{abstract}
Aiming to understand the social representations of people in Sergipe, Brazil about Indians, 378 residents of six cities were interviewed (five cities in Sergipe and one in Alagoas). The results revealed the predominance of a social representation of Indians whose main meaning is formed by elements that refer to a past or remote time or which denote physical and cultural distance (i.e. "woods", "forests", "nudity", painting" etc). In a similar way, when participants were asked about what they recalled of Indians in the Brazilian history, they seldom mentioned recent events and had difficulty to mention even remote facts. Living far away from an Indian tribe had less impact on social representations than what was expected. The conclusion is that for many participants, Indians exist only as an absence or yet in naturalized way, as phenotypic and cultural remnants of a 500-year history of violence and extermination.
\end{abstract}

Keywords: indians, social representation, stereotypes.

\section{Las representaciones sociales construidas de los indígenas en Sergipe}

\begin{abstract}
Resumen: Con el objetivo de se comprender cuales son las representaciones sociales construidas sobre los indígenas, fueran entrevistados 378 habitantes de 6 ciudades (5 en Sergipe y 1 en Alagoas). Las entrevistas fueron hechas em las casas de los residentes. Los resultados indican el predominio de una representación social de los indígenas anclada en el pasado remoto y es demostrada em los signos "bosques", "desnudos", "pintura", y otros más. También cuando se le preguntó el que se recuerda de los indígenas en la historia del Brasil, los entrevistados casi nunca describen acontecimientos recientes y, en muchas veces, ni acontecimientos remotos ellos logran recordar. La ciudad de los entrevistados tuvo menos importancia en las representaciones sociales que lo esperado. Muchos de los entrevistados piensan que los indígenas existen como una ausencia, como expresiones culturales que no han cambiado a pesa $\mathrm{r}$ de los 500 años de historia de violencia y exterminio.
\end{abstract}

Palavras clave: indígenas, representación social, estereotipo.

Os índios estão no Brasil desde antes do nosso surgimento enquanto país; estão em nossos livros, na história da nossa formação cultural, política e geográfica, em nossa língua, em nossa culinária; os índios estão em todas as regiões do país, e mais que tudo isto, eles estão na composição genética do nosso povo. Uma pesquisa feita pela UFMG em 1997, analisando o DNA dos brasileiros, demonstrou que 45

1 Apoio: CNPq, processo 402200/2004 e FAPITEC/Se. Esse texto foi revisado seguindo o Acordo Ortográfico da Língua Portuguesa (1990), em vigor a partir de $1^{\circ}$ de janeiro de 2009.

2 Endereço para correspondência:

Professor Dr. Marcus Eugênio Oliveira Lima, Mestrado em Psicologia Social da UFS, Cidade Universitária Prof. José Aloísio de Campos Av. Marechal Rondon, s/n Jardim Rosa Elze, CEP 49.100-000. São Cristóvão -SE, Brasil.E-mail: meolima@uol.com.br milhões de nós têm ascendência indígena (Pena, CarvalhoSilva, Alves-Silva, Prado, \& Santos, 2000). Por que então, para a maioria dos brasileiros, os índios são invisíveis? Por que raramente ou mesmo nunca nos sentimos "a mão possessa que os supliciou"? Por que tão perto biológica e geograficamente e tão longe em termos de identidade nacional?

Os índios são um grupo minoritário que ocupa uma posição específica em nossa sociedade, algo que se reflete na formação de imagens sobre eles. Esta posição relaciona-se, certamente, com suas caracterizações históricas, construídas pelos grupos detentores do poder político-econômico. Pode-se dizer que as atuais representações sociais dos índios foram construídas pelos não índios ao longo da história de contato que se inicia com o descobrimento do Brasil e se estende com a colonização a que eles foram submetidos e 
que culmina, nos dias de hoje, com a sua invisibilização e exclusão moral e social. Um processo marcado pela dominação, assimilação cultural forçada, violência, desapropriação das terras, expulsão e genocídio.

Os índios parecem estar tão longe de nós quanto da ciência, sobretudo da psicologia. Quando colocamos a palavra "índios" na linha de busca por assuntos no Scielo, encontramos, numa consulta feita dia 18 de abril de 2008, 119 trabalhos publicados em periódicos científicos. Destes 119, 90 artigos, que correspondem a 76,5\%, foram publicados em revistas na área de saúde, analisando aspectos que deixam explícita a situação de exclusão social deste grupo, tais como tuberculose, carência nutricional, mortalidade infantil, anemia, suicídio, alcoolismo, dentre outros. Esse quadro teórico sobre os índios pode levar à inferência de que no Brasil os índios são doentes, alimentam-se mal, são pitorescos e não têm psique. Uma só revista, os Cadernos de Saúde Pública, responde por 60 dessas 90 publicações. Os outros artigos encontrados aparecem em revistas da área de ciências sociais/ antropologia (16), história (sete), educação (quatro) e agricultura (dois). Nenhum registro de trabalho publicado em revistas de psicologia sobre os índios do Brasil foi verificado. Igualmente não encontramos trabalhos sobre preconceito e racismo contra os índios no Brasil nesta nossa pesquisa.

É nesse cenário complexo de silêncio e invisibilização social que habitam e são construídas as representações sociais sobre os índios no Brasil. É sobre esta temática que nos debruçamos a fim de compreender como são percebidos os índios por pessoas que vivem próximas e por outras que vivem distantes deles, assim como o que é um "índio" no imaginário social.

\section{O encontro com o outro e a invenção da diferença}

Jahoda (1999), no livro "A imagem dos selvagens", analisa o modo como se deu o encontro dos europeus com outros povos na época dos descobrimentos. O relato histórico de Jahoda nos diz que os europeus tomavam a sua própria aparência física e sua cultura como critérios de completa humanidade no encontro com o "outro". A cor da pele diferente, a nudez, o tipo de carne que consumiam (incluindo para alguns a carne humana) e outras características negativas a eles atribuídas foram tomados como emblema da sua animalidade. É nessa lógica de ancoragem do novo no velho que se formam as primeiras representações sociais dos índios:

Forçado com o exótico e incompreensível, os europeus tenderam a interpretar o 'outro' através de categorias familiares, como a raça pliniana ou os homens selvagens. Em suma, as imagens dos selvagens foram refratadas sempre nas lentes dos interesses, idéias e valores particulares dos grupos (Jahoda, 1999, p.10).

No caso brasileiro, especificamente, foi com a chegada dos portugueses que ocorreu a inserção dos povos indígenas em nossa história eurocêntrica. Este encontro de civilizações acarretou graves consequências aos povos indígenas, que foram violentamente submetidos a uma nova ordem econômica, cultural e religiosa. Pensamos que esses e outros aspectos da nossa história precisam ser considerados para o entendimento das representações sociais que se constroem sobre os índios no presente.

O Brasil, na visão dos descobridores, era ocupado por um grupo de nativos ingênuos, quase crianças, nus, sem religião, lei ou ordem. A carta de Pero Vaz de Caminha constitui a primeira objetivação ou materialização das representações sociais dos não-índios sobre os índios:

A feição deles é a de serem pardos, maneira de avermelhados, de bons rostos e bons narizes, bem feitos. Andam nus, sem nenhuma cobertura. Não fazem o menor caso de encobrir ou de mostrar suas vergonhas; e nisso têm tanta inocência como em mostrar o rosto (Caminha, 1500/1997, p. 14).

Muitas das representações sociais que foram surgindo dos índios nasceram nesse contexto de estranhamento no encontro dos portugueses com o outro e tornam-se tão fortes e hegemônicas que persistem até a atualidade. Cabe destacar que essas representações sociais da alteridade utilizam na sua produção os elementos físicos ou culturais dos grupos e são atravessadas por interesses simbólicos e materiais. Como refere Miles (1989), na mesma época dos descobrimentos europeus, as representações do outro construídas sobre os africanos ancoravam-se, sobretudo, em questões culturais, especificamente nos aspectos de suas vidas que eram mais repelentes aos europeus e que permitiam negar a existência de uma "humanidade comum". Em relação aos bárbaros e aos islâmicos raramente era feita qualquer referência à sua aparência física; eram enfatizadas a cultura e a religião como elementos centrais através dos quais se estabelecia a dialética do Eu com o Outro e da diferenciação e inferiorização. Miles (1989, p. 25), analisando os índios, afirma:

As classes européias envolvidas neste processo reconstruíram as representações destas populações indígenas, a fim de legitimar suas ações e responder às suas experiências com elas. Era um complexo de articulação entre a justificação dos interesses e estratégias de uma classe e a observação empírica de mudanças situacionais. A representação do outro que resulta deste processo era homogénea, mas não estática.

Essa "escolha" de elementos na bricolagem de uma representação social parece atender ao princípio teórico da seleção e descontextualização que se constitui em uma das fases da objetivação. Esse processo precede a formação de um núcleo figurativo ou imagem pictórica do grupo. Assim, se no caso do estudo seminal de Moscovici (1961/1978) sobre a representação social da psicanálise essa materialização do abstrato era alcançada pela imagem do conflito entre o 
inconsciente e o consciente para produzir um recalque e em seguida um sintoma, no caso da representação social dos índios na época da colonização, a materialização se opera por meio da imagem de "cadeias do ser" ou hierarquias de evolução dos grupos, como nos mostra o Frei Bartolomeu de Las Casas (1474-1566/2001), quando retrata o extermínio dos índios na América espanhola: Índios : espanhóis crianças:adultos $\cong$ macacos:seres humanos.

Um passo seguinte na objetivação ou materialização de uma representação social é a naturalização. Esta permite tornar não apenas o abstrato em concreto, através da sua expressão em imagens; mas a própria representação em realidade (Vala, 2000), transformando, nas palavras de Moscovici (2005, p.71): "a palavra que substitui a coisa, na coisa que substitui a palavra". O modo como se processou a naturalização das imagens dos índios na colonização aparece na descrição feita pelo rei da Bavária, que enviou uma expedição para o Brasil no início do século XIX a fim de estudar esses povos:

O temperamento dos índios é assim não desenvolvido e manifesta-se como viscoso. Todos os processos mentais, e até mesmo a alta sensibilidade, aparecem em estado de paralisia. Eles vivem sem refletir sobre o todo da criação, sobre as causas e internas conexões entre as coisas, seus sentidos dirigem-se apenas para a auto-preservação (Jahoda, 1999, p. 22).

Assim, as representações dos índios que remetem ao período colonial são, num primeiro momento, de um índio ingênuo, sem religião, como crianças a serem educadas e que imitavam as ações dos portugueses. Esta imagem justificava o papel missionário dos padres Jesuítas, que deveriam conduzir "essas crianças" pelos caminhos da fé católica e da "salvação". Desse modo, o interesse colonizador seria alcançado pela doutrinação religiosa.

Outro fato notável é de como a percepção dos índios pelos colonizadores muda dependendo dos interesses envolvidos na relação de dominação. Trata-se de um modo de descrição indígena que serve de suporte cultural para justificar, ora as ações de catequese, colocando os índios como crianças dependentes e ingênuas, ora a caça e o extermínio, colocando os índios como selvagens, canibais e sanguinários. Estas duas retóricas ou formas de representação do índio convivem harmonicamente no imaginário colonial brasileiro. Uma evidência disto seria a visão dos índios que se deixaram converter e "salvar" pela fé cristã, estes denominados na época de "gentios" (Alexandre, 1999) e os que permanecem selvagens e, por isto, são caçados e exterminados.

\section{$O$ índio bom e o índio mau nas representações sociais}

A colonização foi sempre marcada por violência e relações de conflito. No Brasil, o europeu inicia uma colonização que tem por marca a ocupação das terras através da violência e expulsão dos índios de seus territórios e o anseio de utilizar a mão-de-obra indígena para suprir seus interesses econômicos. Várias guerras contra os índios foram classificadas na época como "guerras justas", mesmo quando eram apenas meios de obter escravos e outros recursos econômicos. Foram muitas as guerras travadas com esse intuito, ainda que no discurso oficial os índios devessem ser tratados com brandura.

É nesse sentido que o historiador português António Hespanha (2001) destaca a influência do catolicismo na colonização portuguesa. Diferentemente do que ocorreu nos outros países da América do Sul e Central colonizados pela Espanha, onde o extermínio dos índios era feito sem preocupações cristãs (Las Casas, 1474-1566/2001), no Brasil a exploração e mortandade indígena eram feitas com o verniz da "cordialidade" ou, no sentido que mais tarde Gilberto Freyre (1933/1983) consagraria, de um modo "luso-tropicalista" ou "benevolente" (ver Alexandre, 1999, para uma discussão crítica). Essa ambivalência é notada por Darcy Ribeiro (1996a, p. 120) quando diz: "A doçura mais terna e a crueldade mais atroz aqui se conjugaram para fazer de nós a gente sentida e sofrida que somos e a gente insensível e brutal, que também somos."

A ambivalência na representação social do índio tem impacto nas políticas indigenistas implementadas no Brasil. A legislação no período colonial oscilou entre os interesses dos colonos, que desejavam escravizar os índios, e os esforços dos missionários, que tencionavam transformá-los em cristãos civilizados e, portanto, mais dóceis ao processo colonizador. As leis que surgiram no período tentavam conciliar esses interesses, demonstrando alguma ambivalência. Em 30 de junho de 1609, o rei de Portugal declara livre todos os índios do Brasil para tentar coibir as escravizações ilícitas, mas dois anos depois, na lei de 10 de setembro de 1611, restaura a guerra justa e a escravidão dos índios ditos hostis. Essa ambivalência permanece até séculos depois. Uma carta régia, de 30 de junho de 1721, do vice-rei do Brasil, referindo-se aos índios não-assimilados, afirmava que era preciso extingui-los, fazendo apelo veemente de guerra aos "bárbaros" (Cunha, 1992).

O "índio bom" foi elemento de inspiração literária e construção de identidade no período do Romantismo literário. O movimento romântico dos séculos XVIII e XIX tomou o índio como seu objeto de mitificação. As representações sociais do índio objetivavam-se numa visão idealizada desse grupo: um índio herói, nacionalista, corajoso e guerreiro. Até hoje essas representações sociais repercutem no imaginário nacional e na permanente tentativa de construir uma identidade brasileira. O romance O Guarani, de José de Alencar, e os poemas "Juca Pirama" e "Deprecação", de Gonçalvez Dias, ilustram bem esse processo de idealização do índio.

É importante ainda ressaltar que a representação social do índio se transforma também em função dos contextos geográficos da interação. Pessoas que vivem em regiões mais 
urbanas podem ter uma imagem do índio diferente das pessoas das áreas mais rurais, sobretudo se umas tiverem mais contato com os índios que outras. Como afirma Ribeiro (2005), aquilo que para o Brasil do litoral é história remota, para o Brasil do interior pode ser a crônica atual.

Torres e cols. (2007) realizaram um estudo das representações sobre os índios em duas cidades de Goiás: uma onde existe um aldeamento urbano e os índios frequentam as escolas públicas e outra onde não existe nenhum tipo de contato entre indígenas e não-indígenas. As autoras observaram que existe mais preconceito contra os índios na cidade onde há mais contato com eles do que na cidade onde não há contato. As explicações para esse dado abordam a percepção de competição por recursos materiais e simbólicos entre índios e não-índios quando convivem mais próximos.

\section{Os índios hoje: extermínio, invisibilização e resistência}

No processo de colonização estima-se, visto que não há registros oficiais sistemáticos, que milhões de índios tenham sido mortos em confrontos por suas terras, que outros tantos foram capturados para trabalhar como escravos e que muitos ainda fugiram para o interior do país. O extermínio do índio no Brasil atinge seu ápice na década de 1960, quando restavam apenas 100 mil índios (Ribeiro, 1996b). No Nordeste, os povos indígenas foram considerados extintos em meados do século XIX (Silva, 2006).

Esse extermínio começa a regredir a partir de 1950 graças à resistência indígena. Ribeiro (2005) afirma que tal resistência, ainda que seja marcada pela perda de traços culturais originais, produz um índio mais forte e resiliente ao contato com a cultura dominante. É nesse contexto de resistência e aculturação que surge o fenômeno da transfiguração étnica. Este termo foi criado por Ribeiro (2005) para explicar o processo de formação de uma nova identidade indígena, um novo modo de ser e viver que os índios adquirem no contato com os brancos, pois adotam novos valores, normas e costumes; no entanto permanecem com um sistema de valores, mitos e rituais que ainda os mantêm como "índios".

Muitos índios se convertem em trabalhadores assalariados ou em produtores de alguma mercadoria porque precisam de recursos para comprar ferramentas, remédios, panos e outros artigos de que necessitam. Mas, ainda assim, permanecem índios, porque se identificam e são aceitos como membros de sua comunidade indígena de origem antiqüíssima (Ribeiro, 2005, p. 13).

Algo em torno de 1.300 línguas indígenas diferentes eram faladas no Brasil há 500 anos. Atualmente, estima-se que haja cerca de 225 sociedades indígenas que perfazem cerca de $0,25 \%$ da população brasileira, totalizando cerca de 460 mil indivíduos distribuídos em aldeias situadas no interior do território nacional, falando cerca de 180 línguas distintas e pertencentes a mais de 30 famílias linguísticas diferentes (Fundação Nacional do Índio [FUNAI], 2008). Outras estimativas referem que, além desses, há entre 100 e 190 mil vivendo fora das terras indígenas, inclusive em áreas urbanas. Há também indícios da existência de mais ou menos 63 grupos ainda desconhecidos, além de existirem grupos que estão requerendo o reconhecimento de sua condição indígena junto ao órgão federal indigenista. Assim, a principal característica da população indígena brasileira é sua heterogeneidade cultural.

Todavia, o ressurgimento demográfico do índio no Brasil ainda não tem implicado visibilidade social desse grupo. No nível das percepções sociais, os índios permanecem sendo vítimas de preconceitos e discriminação na sociedade brasileira. O preconceito em relação aos indígenas ocorre no meio rural e urbano; além disso, os índios são quase que excluídos dos processos de formação da identidade nacional. Esta seria uma das principais causas do não-reconhecimento dos índios; o índio teria ficado em terceiro lugar ou mesmo em lugar nenhum, como um "não-cidadão", como um resíduo, numa posição talvez ainda pior que a dos negros que, em nossa sociedade racista, são vistos como cidadãos de terceira ordem (Agüero, 2002). Esta seria a lógica da invisibilização do índio brasileiro.

Oliveira Júnior (1999) afirma que a estratégia de invisibilização consiste numa tentativa de obliterar a diversidade étnica, produzindo uma recusa ou negação da identidade étnica, a fim de produzir uma homogenização dos grupos, tal como acontece contra os negros: "Historicamente, a sociedade colonial brasileira teria escamoteado diferenças entre práticas culturais de brancos e negros, como forma de retirar das mesmas sua virtualidade política, seu potencial como marca de alteridade" (Oliveira Junior, 1999, p. 166).

Trilhando o caminho das análises das ligações sociais que Simmel (1950) realiza no "Estrangeiro", podemos considerar a importância da distância espacial e simbólica, sobretudo da primeira, na construção das representações sobre os grupos e pensar uma espécie de "geometria das relações sociais". Na análise de Simmel (1950) é destacada a ambivalência do estrangeiro no seio do grupo, como alguém que está geograficamente próximo e simbolicamente distante. Existe ainda, para Simmel, um tipo de estrangeiro que, por não ocupar o mesmo espaço simbólico que os autóctones, não entra nos processos de comparação e de contraste que produzem as lógicas identitárias. Nesses casos, e o exemplo usado por Simmel é o da relação entre gregos e bárbaros, estabelece-se um tipo de "não-relação", pois não existe alguém que se poderia perceber como membro de outro grupo, existe um alguém que sequer é concebido como membro da espécie humana.

Jodelet (1998), analisando a construção da alteridade numa perspectiva psicossocial, vai afirmar que a noção de 
alteridade está sempre no contraponto entre "o não eu de um eu" e "o outro de um mesmo". Jodelet (1998) diferencia a "alteridade de fora", definida como aquela construção e exteriorização da diferença que representa o "outro" como longínquo e exótico, em relação à cultura do grupo; e a "alteridade de dentro", aplicada àqueles que, embora sejam diferentes dos dominantes, seja na cor, na etnia, ou na compleição física, estão ligados a estes por terem pelo menos um pertencimento social comum (nacional, étnico, comunitário, religioso); mas ao mesmo tempo se diferenciam ou desviam em outros aspectos e por isso podem ser considerados como fonte de mal-estar ou de ameaça.

A alteridade pode ser radicalizada quando a diferença atribuída ao outro transforma-se em "essência negativa". Nas palavras de Jodelet (1998, p. 51), "O trabalho de elaboração da diferença é orientado para o interior do grupo em termos de proteção; para o exterior, em termos de tipificação desvalorizante e estereotipada do diferente". Pensamos que, no caso da percepção dos índios por outros brasileiros, ou não se configura um campo de produção da alteridade, porque não se reconhece um universo simbólico comum ou compartilhado, ou se estabelece, no caso das relações de competição, uma radicalização da alteridade.

Como afirma o fotógrafo e antropólogo Amorim (n.d.), parece que amamos ou aprendemos a cultuar um índio genérico, estereotipado, que anda nu e vive nas matas da Amazônia; ou seja, amamos o índio distante e improvável, o "índio total". Os índios particulares e reais, ainda segundo Amorim (n.d.), que transitam nas periferias urbanas, semiurbanas, rurais, entre suas aldeias, a selva e as bancadas parlamentares, têm a difícil missão de criar paralelos entre seus espaços étnicos e o mundo que os rodeia, entre a imagem demandada por esses espaços sociopolíticos e a imagem visual que tentam construir com a finalidade de se autoidentificarem e serem identificados.

Nesse embate de "ressurgência", "transfiguração" e "aculturação", os povos autóctones têm duas alternativas impostas pelos dominantes: mantêm-se "índios" nas matas para desocuparem os espaços sociais nacionais ou ocupam os espaços sociais para deixar de serem "índios".

\section{Os índios em Sergipe}

Em Sergipe, a situação não é muito diferente da que se dá no resto do país. Em nosso estado resta apenas uma tribo, a dos índios Xokós, formada por cerca de 250 indivíduos que residem na Ilha de São Pedro, município de Porto da Folha. Eles vivem principalmente da agricultura, pecuária, pesca e artesanato; integraram-se ao comércio local e fazem visitas constantes aos municípios de Pão de Açúcar e Porto da Folha, onde compram e vendem mercadorias.

Os Xokós são remanescentes de vários outros grupos indígenas. A região do São Francisco era habitada em 1587 pelos Caetés e pelos Tupinambás. Porém, alguns deles foram escravizados e levados para a região que hoje é o estado da Bahia e outros perderam, aos poucos, características fenotípicas indígenas devido à mistura com outros povos. No século XVII surgem os aldeamentos de São Pedro e Pacatuba, tendo ambos dado abrigo aos índios Xokós (ver Diniz, 1991; Figueiredo, 1981, para revisões).

Beatriz Góis Dantas (1991) afirma que o aldeamento de São Pedro surgiu a partir de uma missão que os capuchinhos instituíram às margens do rio São Francisco para catequizar os índios Aramuru. Os Aramuru lutaram como aliados aos portugueses para a expulsão dos holandeses da região do São Francisco. Como forma de recompensa receberam meios de subsistência e uma faixa de terra. Os Xokó descendem desses grupos e dos Cariri que migraram para Alagoas.

É na análise da percepção de si e do outro, da construção da alteridade e hierarquização da diferença que circulam os interesses desta pesquisa, cujo objetivo é investigar as representações sociais que moradores não-indígenas de Sergipe constroem sobre os índios, bem como o impacto que morar próximo ou distante da única tribo do estado tem nessas representações. Nossas hipóteses de trabalho são: 1) as representações sociais do índio serão de um índio distante, vivendo em matas ou florestas e 2) os moradores das cidades mais próximas à única tribo indígena do estado (Porto da Folha e Pão de Açúcar) construirão representações sociais mais ancoradas na ideia do "índio mau" e ameaçador, tendo em vista possíveis relações de competição material que se estabeleçam.

\section{Método}

Neste trabalho adotamos, sobretudo, a abordagem estrutural, de acordo com a qual não apenas o conteúdo de uma representação, mas também a sua organização devem ser pesquisados. Isto pode ser feito mediante técnicas que permitam o "desenho" da estrutura da representação, seja com base na produção do próprio sujeito, ao qual é solicitado que realize um trabalho cognitivo de análise, comparação e hierarquização dos dados produzidos, seja a partir da reordenação realizada pelo próprio pesquisador sobre os mesmos dados (Oliveira, Marques, Gomes, \& Teixeira, 2005).

Nessa perspectiva, a representação é entendida como um campo simbólico estruturado em elementos hierarquicamente organizados, sendo alguns mais centrais e outros mais periféricos. Esse enfoque, desenvolvido por Flament e Abric, no final da década de 1980, realça os aspectos estruturais da representação. Para Abric (1994), as representações possuiriam um Núcleo Central (NC) e um sistema periférico. O NC cria, organiza e transforma a representação; é ele também que diferencia uma representação de outra.

De acordo com Echabe (1994), duas representações podem ser idênticas na periferia do seu sistema simbólico, mas nunca no NC. Abric (1994) propõe uma metodologia de pesquisa na abordagem estrutural das representações que siga três etapas: 1) encontre os conteúdos ou elementos da 
representação; 2) analise as relações entre os elementos, peso e ordem de importância, e 3) estabeleça o NC. Neste aporte, adota-se também uma abordagem multimétodos, com entrevistas, questionários, técnicas projetivas, mapas associativos.

Todas as normas éticas para realização de pesquisas com seres humanos foram devidamente seguidas, como sugeridas pela Comissão Nacional de Ética em Pesquisa, com base na Resolução CNS n 196/96. Os participantes leram e, quando aquiesceram em colaborar com o estudo, assinaram um Termo de Consentimento Livre e Esclarecido. Os pesquisadores deixaram ainda uma cópia desse termo com cada participante, assinada pelo coordenador da pesquisa, com os objetivos do estudo, métodos de coleta de dados e informações para contato e obtenção dos resultados.

\section{Participantes}

O estudo foi realizado com 378 moradores de seis cidades (Aracaju 129 entrevistados, Estância 58, Itabaiana 34, Lagarto 53, Pão de Açúcar 54 e Porto da Folha, 50 entrevistados) no ano de 2006. Esta amostra é representativa dos 1.784.829 moradores de Sergipe (Instituto Brasileiro de Geografia e Estatística, 2000) a um intervalo de confiança de $5 \%$. As cidades foram escolhidas por serem as principais das microrregiões do estado (Lagarto, Itabaiana e Estância), por ser a capital do estado (Aracaju) ou por serem as mais próximas da tribo indígena de Sergipe (Porto da Folha e Pão de Açúcar). Com efeito, a ilha de São Pedro, local onde vivem os Xokós, fica à beira do rio São Francisco, margeada de um lado pelo município de Pão de Açúcar e do outro pelo município de Porto da Folha.

Os entrevistados foram, em sua maioria, mulheres $(52,3 \%)$, com idades entre 16 a 83 anos (Média $=34,6$ anos, Desvio Padrão $=15$ ), com renda familiar mensal que variou de menos de um salário mínimo $(9,8 \%)$ até mais de nove salários $(12 \%)$, sendo a faixa de renda mais freqüente a compreendida entre um e dois salários mínimos (42,3\%). A escolaridade dos entrevistados variou de analfabeto $(3,2 \%)$ até nível superior completo $(16,6 \%)$, sendo que a maioria $(31,9 \%)$ tem ensino médio completo. Dos 378 entrevistados, 85 disseram ter parentes indígenas e 281 disseram não ter ou não saberem se tinham, sendo que 12 pessoas não responderam a esse questionamento.

\section{Procedimento}

As entrevistas foram individuais e ocorreram nas moradias das pessoas em cada uma das seis cidades. As ruas e casas foram escolhidas de modo aleatório, sendo geralmente as mais próximas dos terminais hidroviários ou rodoviários das cidades. $\mathrm{O}$ roteiro da entrevista era composto de perguntas abertas e fechadas, contendo: associações livres com a palavra "índios", os participantes poderiam fazer até 3 enunciações; questões sobre a memória de acontecimentos históricos do Brasil envolvendo os índios e ainda os sentimentos em relação aos indígenas.

Para a análise da centralidade das enunciações multiplicamos a freqüências por 3 (quando era a $1^{\mathrm{a}}$ enunciação), por 2 (para a $2^{\mathrm{a}}$ enunciação) ou por 1 (para a $3^{\mathrm{a}}$ enunciação), em seguida somamos os valores e dividimos por 100 para construir o índice da força da enunciação; de modo que, por exemplo, uma palavra que foi citada 10 vezes em primeiro lugar, 5 vezes em segundo e 3 vezes em terceiro tem força de enunciação igual a $(10 \times 3)+(5 \times 2)+(3 \times 1) / 100=0,43$.

\section{Análise dos dados}

Utilizamos análise de conteúdo seguindo os procedimentos sugeridos por Bardin (1977), para análise das respostas às perguntas abertas. Consideramos, portanto, três fases de análise: 1) a pré-análise, 2) a exploração do material e 3) o tratamento dos resultados, a inferência e a interpretação. Todos os dados obtidos foram analisados com o auxílio do SPSS, tendo sido realizadas análises descritivas para o teste da primeira hipótese e Testes Qui-Quadrado e Análise de Variância envolvendo a cidade dos moradores para o teste da segunda hipótese.

Primeiramente, pesquisamos, através de uma associação-livre, que evocações a palavra "índios" produzia nos sergipanos. Procedemos então a uma análise da frequência de cada enunciação e de sua centralidade, uma vez que os participantes do estudo poderiam mencionar até três associações com a palavra-estímulo.

\section{Resultados e Discussão}

Os resultados, apresentados na Tabela 1, indicam que a representação social construída pelos sergipanos sobre os índios baseia-se, sobretudo, na pressuposição de uma distância cultural e espacial. Tanto que, a evocação mais comumente produzida foi a das "práticas culturais", com 33\% das repostas, categoria esta formada por termos que fazem referência a um índio exótico, com hábitos e práticas diferentes. Esta também foi a evocação mais central. 
Tabela 1

Representações sociais dos índios na etapa da associação-livre

\begin{tabular}{|c|c|c|}
\hline "Quando você ouve a palavra "Índios", quais são as três primeiras coisas em que você pensa?" & $\begin{array}{l}\text { Frequência de } \\
\text { evocação }\end{array}$ & $\begin{array}{l}\text { Centralidade de } \\
\text { evocação }\end{array}$ \\
\hline $\begin{array}{l}\text { Práticas culturais e diferença (língua diferente, hábitos, pintura, desfile, cantam e dançam, religião, } \\
\text { rituais, banho de rio) }\end{array}$ & 318 & 6,14 \\
\hline Passado remoto (descobrimento do Brasil, primeiros habitantes, antiguidade, nativo, portugueses) & 92 & 2,44 \\
\hline $\begin{array}{l}\text { Natureza (mata, mato, selva, floresta, faz parte da mata Atlântica, árvores, rio, vivem na mata, peixe, } \\
\text { urso, macaco) }\end{array}$ & 78 & 1,79 \\
\hline Explorados/escravizados (maltratados pelos brancos, vida triste, sem perspectiva de vida) & 66 & 1,21 \\
\hline $\begin{array}{l}\text { Direitos iguais (merecem respeito, filhos de Deus, têm direitos iguais, o Brasil deve respeitar, } \\
\text { merecem mais atenção dos políticos, patrimônio da humanidade, deixaram aprendizado) }\end{array}$ & 58 & 1,03 \\
\hline $\begin{array}{l}\text { Exclusão/pobreza (fome, miséria, analfabetos, abandonados, desvalorizados, rejeitados, desigualdade, } \\
\text { desprotegidos) }\end{array}$ & 40 & 0,78 \\
\hline Primitivos (não sabem lidar com as pessoas da cidade, selvagens, não-civilizados, rudimentares) & 37 & 0,82 \\
\hline $\begin{array}{l}\text { Modos de vida (vivem do próprio trabalho, vivem ao ar livre, sabem viver sem coisas materiais, modo } \\
\text { de viver diferente, comunidades, coletividade, natural, sobrevivência) }\end{array}$ & 37 & 0,70 \\
\hline $\begin{array}{l}\text { Caracteres morais (sabidos, espertos, lealdade, trabalhador, honesto, gente boa, carinho, esforçados, } \\
\text { dignidade, solidariedade, afeto) }\end{array}$ & 30 & 0,72 \\
\hline $\begin{array}{l}\text { Isolados/desconhecidos (vejo mais na TV, pessoas não conhecidas, afastados, Amazônia, Bahia, } \\
\text { reserva indígena, isolamento) }\end{array}$ & 29 & 0,56 \\
\hline Caracteres físicos/raça (mestiço, aparência física, raça, cor de terra, cabelo) & 23 & 0,57 \\
\hline Exóticos (saúde, coisa boa coisa bonita de se ver, satisfação, orgulho, interessante) & 23 & 0,57 \\
\hline Guerreiros (resistências, valentia, força e coragem que têm para viver) & 18 & 0,38 \\
\hline $\begin{array}{l}\text { Ruins (brigam entre si, invasores, não se pode esperar nada de bom deles, moleques, maloqueiros, } \\
\text { aproveitadores, malandros, feios, preguiçosos) }\end{array}$ & 17 & 0,39 \\
\hline Perderam a cultura (estuda, novos hábitos, saída para as cidades, semicatequizados) & 16 & 0,28 \\
\hline $\begin{array}{l}\text { Jeito natural (Ingênuos, inocentes, inofensivos, puros, tranquilos, pessoas felizes, originalidade, } \\
\text { simplicidade, naturalidade) }\end{array}$ & 16 & 0,30 \\
\hline Animalescos (canibais, muito grosseiros, agressividade, medo, fisionomia de macaco, violentos) & 11 & 0,21 \\
\hline Benefícios do governo/FUNAI (dinheiro perdido do governo, incentivos do governo, FUNAI) & 11 & 0,17 \\
\hline Extinção/genocídio (existem poucos hoje em dia, minoria, massacre) & 11 & 0,20 \\
\hline Xokós/família (bisavó, descendência, Xokós) & 8 & 0,22 \\
\hline Símbolos nacionais (símbolo do Brasil, Pau-Brasil, bons brasileiros, brasileiro) & 8 & 0,16 \\
\hline Não responde/tautológico (boa parte do mundo tem índios) & 15 & - \\
\hline Total & 962 & - \\
\hline
\end{tabular}

A representação do "índio distante" também aparece como a segunda evocação mais frequente, com $9 \%$, referindose ao índio num passado histórico remoto do Brasil. A terceira evocação mais citada, com $8 \%$, representa o índio distante geograficamente, ocupando as matas, vivendo nas florestas e rios. Chama ainda atenção a percepção dos índios como explorados, escravizados, excluídos socialmente e carentes de direitos, que, somados, correspondem a $17 \%$ das respostas. Também aparecem representações, ainda que com menor frequencia, dos índios animalescos, canibais, ruins, invasores, aproveitadores e maloqueiros, que, somados, totalizam cerca de 6\%. Encontramos ainda 11 respostas que se referem aos índios como aproveitadores ou beneficiários de políticas públicas.

$\mathrm{O}$ fato de existir em Sergipe uma tribo indígena e de 85 dos entrevistados afirmarem ter algum parente indígena teve pouco impacto nas representações sociais construídas; apenas oito enunciações, ou seja, menos de $1 \%$, referiram-se a aspectos mais concretos ou próximos, tais como "bisavô", Xokós" e "descendência".

Como vimos, muitos dos índios atuais vivem nas cidades ou em meios semiurbanos e têm como característica principal uma grande heterogeneidade cultural (FUNAI, 2008). Todavia, a representação social dos índios encontrada neste estudo parece, nos seus núcleos mais centrais, não ter recebido nenhum impacto ou influência dos últimos 500 anos de história. O índio permanece pintado com as cores do exótico, vivendo no mato, como canibais, distantes física, histórica e culturalmente. O que aparece como algo mais "atual" dos índios é uma espécie de ambivalência, que o representa, por um lado, como excluído e carente de direitos, e por outro, como aproveitadores e beneficiários de políticas públicas.

Considerando essa representação social do "índio distante", quase inexistente e invisibilizado, cabe então indagar que papel o fato de os entrevistados morarem perto ou longe da única tribo indígena do Estado teve nessas construções.

A fim de analisarmos os efeitos da cidade do participante sobre a representação social construída do índio, agregamos algumas respostas. Especificamente, juntamos respostas que mencionaram "símbolos nacionais" com as que citaram "questões históricas" e mantivemos este último 
nome. Agregamos ainda respostas referentes a "modos de vida" com "jeito natural" e "natureza". "Guerreiros" e "exóticos" foram integradas à categoria dos traços morais; "animalescos" se juntou com "ruins" para compor a categoria da visão negativa dos índios; "explorados e escravizados" foram agregadas às categorias "extinção e genocídio" e "perderam a cultura", tentando significar um tipo de resposta que ressalta os efeitos negativos do contato com o branco; e "primitivos" foi somada com "isolados". Nas análises que se seguem trabalhamos apenas com as primeiras evocações, de tal forma que a categoria "benefícios do governo/FUNAI" foi citada por ter sido referida apenas uma vez em primeiro lugar.
Essas categorias foram então relacionadas com as cidades de moradia dos sujeitos. Os resultados de um teste Qui-Quadrado indicam que existe um efeito significativo da cidade na representação social do índio, $X^{2}(60)=86.59, p=0,014$.

A representação dos índios em termos de práticas culturais, a qual enfatiza sua diferenciação cultural, é mais comum em Aracaju e Porto da Folha e bem menor em Pão de Açúcar. Por outro lado, a atribuição de traços negativos aos índios (animais/ruins) e ao mesmo tempo a percepção deles como exóticos, belos e carentes de direitos iguais são mais fortes em Pão de Açúcar do que nas outras cidades pesquisadas (ver Tabela 2).

Tabela 2

Representações sociais dos índios e distância espacial

\begin{tabular}{|c|c|c|c|c|c|c|c|c|}
\hline \multirow{2}{*}{ Respostas } & \multicolumn{6}{|c|}{ Cidades } & \multicolumn{2}{|c|}{ Total } \\
\hline & Aracaju & Lagarto & Itabaiana & Estância & Porto da Folha & Pão de Açúcar & $\mathbf{F}$ & $\%$ \\
\hline Práticas culturais & 31,3 & 19,2 & 24,2 & 15,7 & 28,0 & 8,5 & 84 & 23 \\
\hline Exclusão e pobreza & 1,6 & 5,8 & - & 5,9 & 2,0 & 2,1 & 10 & 2,8 \\
\hline Animais/ruins & 3,1 & 3,8 & - & 3,9 & 2,0 & 6,4 & 12 & 3,3 \\
\hline Exploração e Genocídio & 4,7 & 13,5 & 3,0 & 3,9 & 6,0 & 6,4 & 22 & 6,1 \\
\hline Questões históricas & 14,8 & 17,3 & 21,2 & 25,5 & 14,0 & 29,8 & 69 & 19 \\
\hline Direitos iguais & 8,6 & 5,8 & 3,0 & 7,8 & 6,0 & 12,8 & 28 & 7,8 \\
\hline Xókos/ família & - & - & - & - & 8,0 & 4,3 & 6 & 1,7 \\
\hline Natureza/jeito natural & 16,4 & 19,2 & 21,2 & 11,8 & 14,0 & 8,5 & 55 & 15 \\
\hline Caracteres físicos & 4,7 & 3,8 & 9,1 & - & 2,0 & 2,1 & 13 & 3,6 \\
\hline Exóticos/belos/bons & 5,5 & 1,9 & 9,1 & 13,7 & 10,0 & 14,9 & 30 & 8,3 \\
\hline Primitivos/isolados & 7,8 & 9,6 & 6,1 & 7,8 & 2,0 & 4,3 & 24 & 6,6 \\
\hline Não responde/tautológico & 1,0 & - & - & 3,9 & 6,0 & - & 6 & 1,7 \\
\hline
\end{tabular}

Enquanto que, em Pão de Açúcar, cidade onde efetivamente os índios Xokós convivem com os não-índios, as representações sociais sobre eles são ao mesmo tempo negativas e positivas e existe uma maior percepção de que eles devem ser cidadãos, pessoas de direitos, no sentido de Rawls (2003), nas outras cidades, de modo geral, existe uma visão distanciada do índio, neutra, que não cria processos de comparação e que traduz, conforme nosso entendimento, a invisibilidade e indiferença que caracterizam a visão dominante dos brasileiros que não mantêm contato com os índios. Essa visão, se não produz antipatia ou negatividade, também não produz solidariedade em relação a esse grupo. Esses dados parecem confirmar a ideia de Jodelet (1998) de que o "mesmo", "ego" e o outro "alter" só podem opor-se no quadro de um nós, e as ideias de Simmel (1950) sobre a importância da distância espacial na construção das representações sobre o "outro".

Chama ainda atenção o fato de Porto da Folha e Pão de Açúcar serem as cidades em que menos aparece a representação do índio como isolado e primitivo. Nas outras cidades do interior (Estância, Lagarto e Itabaiana) aparecem representações sociais dos índios que se diferenciam pouco das encontradas em Aracaju.

A invisibilização dos índios no imaginário social também é notável, e ainda com mais força, quando perguntamos aos participantes sobre o que lembravam dos índios na história do Brasil. A maior parte das respostas denuncia a ausência de qualquer lembrança histórica dos índios. Com efeito, quase $30 \%$ das respostas a essa questão entraram na categoria de "respostas evasivas", referindo-se a coisas como "fazem parte do Brasil", "na época deles era melhor", "vieram morar no Brasil e foram bem-vindos", "eles fazem muita coisa boa para o Brasil", dentre outras. Aparecem também memórias mais recentes dos índios na história, mas apenas com $11,9 \%$ das respostas, que remontam à luta dos índios com fazendeiros, a queima do índio Galdino em Brasília e a morte por inanição de crianças indígenas em Mato Grosso do Sul. Apenas duas pessoas lembram algo relacionado com a tribo Xokó, referindo-se à luta desta pela terra na Ilha de São Pedro (ver Tabela 3). Vale ressaltar que mais de $16 \%$ dos entrevistados tinham nível superior e que a grande maioria havia concluído o ensino médio. 
Tabela 3

Frequência e percentagens das respostas à pergunta: "Quando você pensa nos acontecimentos do Brasil, o que lembra em relação aos índios?"

\begin{tabular}{|c|c|c|}
\hline Lembranças & $\mathbf{F}$ & $\%$ \\
\hline $\begin{array}{l}\text { Não lembra ou respostas evasivas (fazem parte do Brasil, na época dos índios era melhor e vieram morar no Brasil e } \\
\text { foram bem-vindos) }\end{array}$ & 125 & 27,8 \\
\hline $\begin{array}{l}\text { História nacional antiga ou remota (os portugueses vieram para cá, período em que eles foram escravizados, } \\
\text { catequização dos índios e primeira missa no Brasil) }\end{array}$ & 65 & 14,5 \\
\hline $\begin{array}{l}\text { Sofrimento dos índios (descaso, judiados, injustiça, enganados, falta de cuidado dos brancos, tenho pena deles, falta de } \\
\text { respeito, humilhados e martírio) }\end{array}$ & 64 & 14,3 \\
\hline $\begin{array}{l}\text { Exclusão (ninguém dá mais atenção aos índios, são tratados de modo diferente, são excluídos, esquecidos, } \\
\text { discriminados, falta de acesso e estão acabando) }\end{array}$ & 59 & 13,2 \\
\hline $\begin{array}{l}\text { História nacional atual (luta contra os fazendeiros, conflitos pela terra, queima do índio em Brasília, demarcação das } \\
\text { terras da Amazônia, crianças indígenas morrendo por falta de assistência médica e reportagens) }\end{array}$ & 53 & 11,9 \\
\hline $\begin{array}{l}\text { Surgimento/origem (existem desde o começo, foram raiz de toda nossa raça, eram os donos das terras quando o Brasil } \\
\text { foi descoberto e descobriram o Brasil) }\end{array}$ & 44 & 9,8 \\
\hline $\begin{array}{l}\text { Transfiguração étnica (mudança de raças, conflitos com a civilização, destruição da cultura, aculturação e cultura } \\
\text { modificada) }\end{array}$ & 28 & 6,3 \\
\hline Herança cultural (festas indígenas, cultura, herança cultural, desfiles indígenas e dia do índio) & 8 & 1,8 \\
\hline História regional (briga na Ilha de São Pedro pela terra Xokó) & 2 & 0,4 \\
\hline Total & 448 & 100,0 \\
\hline
\end{tabular}

Os sentimentos intergrupais também são elementos essenciais na construção e reificação das representações sociais. A fim de analisarmos que sentimentos os entrevistados tinham pelos índios, pedimos que atribuíssem notas variando de zero a cinco para uma lista de dez sentimentos: admiração, culpa, simpatia, desprezo, orgulho, pena, respeito, raiva, indiferença e solidariedade. Notas mais elevadas indicavam maior expressão de sentimento dos participantes em relação aos índios do Brasil.

Os resultados indicam que os sentimentos mais fortemente expressos em relação aos índios são os de respeito $(M=4,59, \mathrm{DP}=0,98)$, admiração $(M=4,16, \mathrm{DP}=1,16)$, simpatia $(M=3,97, \mathrm{DP}=1,34)$ e solidariedade $(M=3,92$, $\mathrm{DP}=1,54)$. Em contrapartida, os entrevistados afirmam sentir pouca raiva, desprezo e indiferença em relação aos índios (ver Figura 1).

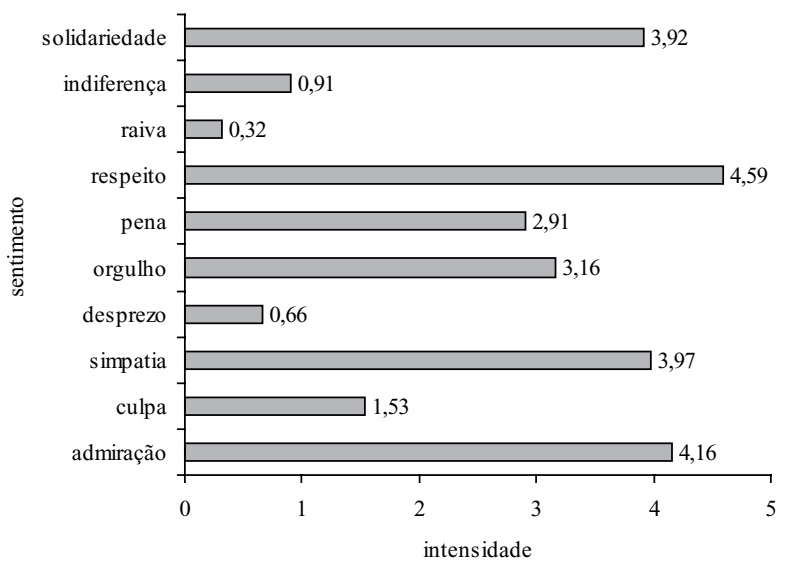

Figura 1. Médias de expressão dos sentimentos em relação aos índios (a escala variou de $0=$ ausência do sentimento a 5 = máxima expressão).
Esses resultados parecem contraditórios em relação ao quadro de outros dados já analisados, pois vimos antes que a representação social dos sergipanos pesquisados sobre os índios era a do índio ausente ou invisível. Todavia, quando perguntados diretamente sobre o que sentem em relação a esse grupo, os entrevistados dizem coisas altamente positivas, quase nada negativo e negam a indiferença. Talvez essa suposta contradição nos dados seja apenas aparente e se deva aos aspectos normativos e às pressões do politicamente correto nas respostas.

De acordo com Menin (2006), existe nas representações sociais uma "zona muda" que se refere a dimensões representacionais que, embora compartilhadas pelos membros de um grupo ou categoria social, raramente são manifestadas ou objetivadas publicamente, pois ferem determinadas normas sociais. Assim, pensamos que elementos desta "zona muda" aparecem mais em questões de enunciação livre do que nessa questão mais fechada sobre os sentimentos.

Analisamos então o efeito da cidade de moradia sobre os sentimentos expressos pelos entrevistados em relação aos índios. Verificamos um efeito significativo da cidade apenas para dois sentimentos: raiva $\left(F_{(5,375)}=2.26, p=\right.$ $0,04)$ e desprezo $\left(F_{(5,377)}=2.29, p=0,04\right)$. Como se pode ver na Tabela 4, existe mais expressão de desprezo pelos índios em Estância e Itabaiana do que em Aracaju e Porto da Folha. Em relação à raiva, esta é mais sentida pelos índios em Estância e Pão de Açúcar do que em Aracaju. 
Tabela 4

Médias de expressão das emoções de raiva e desprezo aos índios em função da cidade de moradia

\begin{tabular}{lcccccc}
\hline \multirow{2}{*}{ Sentimento } & \multicolumn{9}{c}{ Cidade } \\
\cline { 2 - 8 } & Aracaju & Porto da Folha & Itabaiana & Lagarto & Estância & Pão de Açúcar \\
\hline Raiva & $0,16_{\mathrm{a}}$ & $0,24_{\mathrm{ab}}$ & $0,26_{\mathrm{ab}}$ & $0,32_{\mathrm{ab}}$ & $0,53_{\mathrm{b}}$ & $0,58_{\mathrm{b}}$ \\
Desprezo & $0,43_{\mathrm{a}}$ & $0,48_{\mathrm{a}}$ & $0,94_{\mathrm{b}}$ & $0,72_{\mathrm{ab}}$ & $1,09_{\mathrm{b}}$ & $0,70_{\mathrm{ab}}$ \\
\hline
\end{tabular}

*Médias com letras diferentes são significativamente diferentes (Teste Post Hoc LSD $\leq 0,05$ )

Como vimos nos modelos teóricos de distância geográfica de Simmel (1950) e de construção da alteridade de Jodelet (1998), e de acordo com a hipótese geral deste trabalho, a percepção de proximidade pode gerar competição e percepção de ameaça, fazendo emergir uma visão mais negativa do exogrupo. Assim, não surpreende que Pão de Açúcar seja a cidade que apresenta, no geral, a visão mais negativa dos índios, e que Aracaju, por ser a cidade mais urbana de todas, seja a que apresenta uma visão mais positiva dos índios. Merece destaque, no entanto, o fato de que entre os entrevistados de Estância haja também mais desprezo pelos índios do que em outras cidades do interior. Este resultado pode ser uma decorrência de a cidade de Estância ser litorânea e muito próxima ao estado da Bahia, o que pode implicar mais contatos com índios. Cabe ressaltar, contudo, que em cada uma dessas cidades, à exceção de Aracaju, foram entrevistadas pouco mais de 50 pessoas, de tal forma que não temos possibilidades de generalização dos resultados por cidade.

\section{Considerações finais}

O objetivo geral deste trabalho foi analisar as representações sociais que os sergipanos têm a respeito dos índios. Nossas hipóteses de trabalho afirmavam que haveria uma representação social cujo núcleo central seria desenhado por um índio distante. Afirmávamos ainda que os que vivem mais próximos dos índios e têm contato direto com eles construiriam representações sociais mais negativas do grupo, isto por causa das relações de competição por recursos materiais. Os resultados obtidos confirmam as hipóteses levantadas quase que totalmente.

Em consonância com a nossa primeira hipótese, vimos que as representações sociais acerca dos índios construídas pelos sergipanos são predominantemente a do índio distante física, cultural, histórica e emocionalmente. Basta lembrar que o dicionário de termos utilizados pelos sergipanos para se referir aos índios é quase todo constituído de signos que referem à distância, seja física, cultural ou histórica. Diferentemente do que esperávamos, no entanto, mesmo nas cidades mais próximas dos índios, encontramos a mesma representação social do índio ausente ou invisível, do índio de um passado muito remoto da nossa história.

Com efeito, um dado não-verbal muito relevante nesse estudo é o de que muitos entrevistados passavam longos minutos pensando em algo para dizer na questão da associação-livre com a palavra "índios". E mais, dentre os que respondiam encontramos muitas verbalizações evasivas ou tautológicas. Isto nos permite considerar que as representações sociais construídas sobre os índios em Sergipe não sofreram as necessárias atualizações históricas. Ou seria o caso de indagar se existe uma representação social do índio em Sergipe?

As muitas imposições culturais a que os índios foram submetidos e sua resistência e transfiguração étnica passam quase despercebidas nas representações sociais encontradas. Esse "índio novo" e real não é reconhecido como índio pela maior parte dos pesquisados; para eles existe apenas um índio imaginado. Alguns comentários emblemáticos dessa imagem foram feitos durante as entrevistas na cidade de Pão de Açúcar. Era comum ouvirmos frases do tipo: "índios são só os que pintam a cara, andam nus e vivem nas matas, estes aí (os Xokós), que vivem na ilha, não são índios".

Como afirma Cabecinhas (2004), as representações sociais ligam-se aos sistemas de crenças, ideologias, ciência e cultura de uma sociedade, sendo construídas, transformadas e difundidas com ampla influência dos meios de comunicação de massa. No Brasil, essa representação social do índio ausente, homogêneo e quase inexistente continua sendo veiculada pelos meios de comunicação de massa e em outros canais de difusão ideológica. Em nossos livros didáticos, por exemplo, pouco se ouve falar sobre a história atual dos índios e das consequências do contato entre eles e os portugueses no passado e eles e os outros brasileiros no presente. Os índios permanecem, cinco séculos depois do descobrimento, ignorados, desconhecidos e estrangeiros num país talvez mais deles do que dos outros brasileiros.

Em investigações futuras, pretendemos aprofundar os elementos históricos das formações culturais de cada cidade na produção das representações sociais acerca dos índios, especificamente no caso de Estância. Interessa-nos ainda comparar as representações sociais sobre os índios com aquelas construídas sobre outros grupos estigmatizados, tais como negros, ciganos e homossexuais, a fim de entendermos melhor as diferenças e semelhanças nas lógicas de produção da alteridade em relação a essas categorias sociais.

\section{Referências}

Abric, J-C. (1994). Pratiques sociales et représentations. Paris: Presses Universitaires de France. 
Aguero, O. A. (2002). Sociedades indígenas, racismo y discriminación. Horizontes Antropológicos, 8(18), 255-264.

Alexandre, V. (1999). O império e a ideia de raça (séculos XIX e XX). In J. Vala (Coord.), Novos racismos: Perspectivas comparativas (pp. 133-144). Oeiras: Celta.

Amorim, S. S. de (n.d.). Notas etnográficas: A construção da auto-imagem de povos indígenas ressurgidos. Recuperado em 8 março 2007, de http://www.studium. iar.unicamp.br/13/ressurgidos/2.html.

Bardin, 1. (1977). Análise de conteúdo. Lisboa: Edições 70.

Cabecinhas, R. (2004). Representações sociais, relações intergrupais e cognição social. Paidéia (Ribeirão Preto), $14,125-137$.

Caminha, P. V. (1500/1997). Carta a el-rei D. Manuel sobre o achamento do Brasil. Lisboa: Editora EXPO 98.

Cunha, M. C. (1992). História dos índios no Brasil (2a ed.). São Paulo: Companhia das Letras.

Dantas, B. G. (1991). Os índios em Sergipe. In D. M. de F. L. Diniz (Coord.), Textos para a história de Sergipe (pp. 55-57). Aracaju: Universidade Federal de Sergipe/ BANESE.

Diniz, D. M. J. L. (Coord). (1991). Textos para a história de Sergipe. Aracaju: Universidade Federal de Sergipe/ Banese.

Echebarria Echabe, E. A. (1994). Comments on JeanClaude Abric's (1994) book on "pratiques sociales et representations". Papers on Social Representations, 3, 1-6.

Figueiredo, A. (1981). Enforcados: O índio em Sergipe. Rio de Janeiro: Editora Paz e Terra.

Freyre, G. (1983). Casa-grande e senzala: Formação da família brasileira sob o regime de economia patriarcal. Lisboa: Edição Livros do Brasil. (Original publicado em 1933)

Fundação Nacional do Índio. (2008). Retirado em 21 janeiro 2008, de http://www.funai.gov.br/.

Hespanha, A. M. (2001). Luís Molina e a escravidão dos negros. Análise Social, 157, 937-960.

Instituto Brasileiro de Geografia e Estatística. (2000). Retirado em 21 janeiro 2008, de http://www.ibge.gov.br/.

Jahoda, G. (1999) Images of savages: Ancient roots of modern prejudice in western culture. London: Routledge.

Jodelet, D. (1998). A alteridade como produto e processo psicossocial. In A. Arruda (Org.), Representando a alteridade (pp. 47-67). Petrópolis: Vozes.

Las Casas, B. (2001). O paraíso destruído: A sangrenta história da conquista da América. Porto Alegre: L \& PM. (Original de 1474-1566)

Menin, M. S. de S. (2006). Representação social e estereótipo: A zona muda das representações sociais. Psicologia: Teoria e Pesquisa, 22, 43-52

Miles, R. (1989). Racism. Londres: Routledge.

Moscovici, S. (1978). Representação social da psicanálise. Rio de Janeiro: Zahar.

Moscovici, S. (2005). Representações sociais (3a ed.). Petrópolis: Vozes.
Oliveira Junior, A. N. O. (1999). A invisibilidade imposta e a estratégia da invisibilização entre negros e índios uma comparação. Trabalho apresentado no V Congresso Afro Brasileiro, Salvador. Recuperado em 20 março 2008, de http://www.unb.br/ics/dan/geri/boletim/oliveira_jr_1 997.pdf

Oliveira, D. C. de, Marques, S. C., Gomes, A. M. T., \& Teixeira, M. C. T. V. (2005). Análise das evocações livres: Uma técnica de análise estrutural das representações sociais. In A. S. P. Moreira, B. V. Camargo, J. C. Jesuíno, \& S. M. Nóbrega (Orgs.), Perspectivas teórico-metodológicas em representações sociais (pp. 573-603). João Pessoa: Editora da UFPb.

Pena, S. D. J., Carvalho-Silva, D. R., Alves-Silva, J., Prado, V. F., \& Santos, F. R. (2000). Retrato molecular do Brasil. Ciência Hoje, 27, 16-25.

Rawls, J. (2003). Justiça como equidade. São Paulo: Martins Fontes.

Ribeiro, D. (1996a). O povo brasileiro: A formação e o sentido do Brasil (2a ed.). São Paulo: Companhia das Letras.

Ribeiro, D. (1996b). Sobre a mestiçagem no Brasil. In L. M. Schwarcz \& R. da S. Queiroz (Orgs.), Raça e diversidade (pp. 187-211). São Paulo: EDUSP.

Ribeiro, D. (2005). Os índios e a civilização: A integração das populações indígenas no Brasil. São Paulo: Companhia das Letras.

Silva. D. (2006). Racismo, preconceito e imagens sociais dos índios (Relatório do PIBIC). São Cristóvão, SE: Universidade Federal de Sergipe.

Simmel, G. (1950). The sociology of Georg Simmel. New York: Free Press.

Torres, A. R., Matignoni, T. V. L., Rabelo, I. V. M., Campos, R., Camargo, K. de F., Araújo, C. M. G., Duarte, J. C. D., Menegatti, G., \& Oliveira, L. E. C. (2007). Relações entre culpa e constrangimento coletivos e o preconceito contra povos indígenas. Anais do Congresso Norte-Nordeste de Psicologia, 5, 1 .

Vala, J. (2000). Representações sociais e psicologia social do quotidiano. In J. Vala \& M. B. Monteiro (Orgs.), Psicologia social (4a ed., pp. 457-502). Lisboa: Fundação Calouste Gulbenkian.

Marcus Eugênio Oliveira Lima é Professor Adjunto do Departamento de Psicologia da Universidade Federal de Sergipe.

Alan Magno Matos de Almeida é mestrando pelo Programa de Pós-graduação em Psicologia Social da Universidade Federal de Sergipe.

Recebido: 21/08/2008

$1^{a}$ revisão: 04/05/2009

$2^{a}$ revisão: $29 / 07 / 2009$

Aceite final: 07/08/2009 